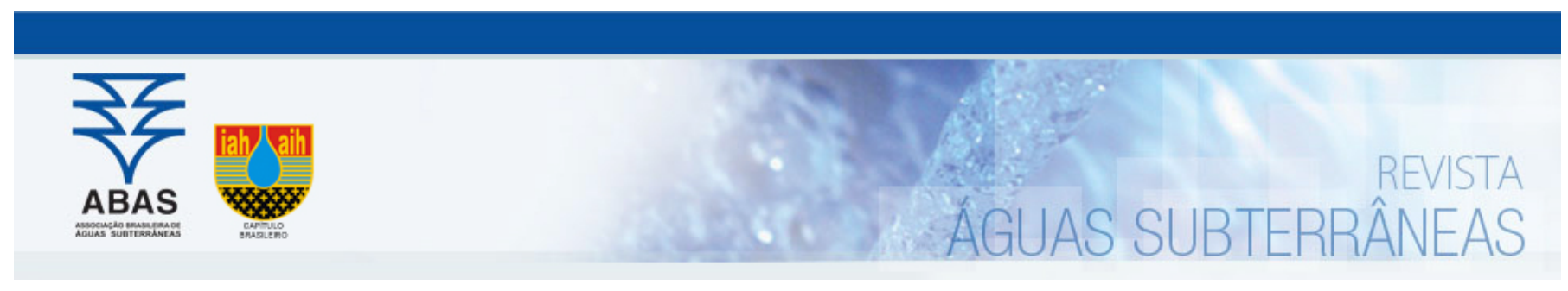

Artigos

\title{
Efeito da descontinuidade estrutural na hidrogeoquímica do aquífero Barreiras no nordeste do Brasil
}

\section{Effect of structural discontinuity on the hydrogeochemistry of the Barreiras aquifer in northeastern Brazil}

\author{
Paula Stein¹; Natalina Maria Tinoco Cabral2; João Manoel Filho3; Leandson Roberto Fernandes Lucena4 ${ }^{4} \bowtie$ \\ 1 Universidade Federal de Campina Grande, Campina Grande \\ 2 Fundação Nacional de Saúde \\ 3 Universidade Federal de Pernambuco \\ 4 Universidade Federal do Rio Grande do Norte \\ $\bowtie$ paula.stein@gmail.com, natalinacabral@gmail.com, jmfilho@ufpe.br, leandson@geofisica.ufrn.br
}

Resumo

Palavras-chave:

Aquífero Barreiras.

Descontinuidade estrutural.

Hidrogeoquímica.

Grupo de águas.

\begin{abstract}
O aquífero Barreiras no campo de poços de Boa Cica, localizado no município de Nísia Floresta/RN, é composto por rochas siliciclásticas com espessura média da ordem de 65 metros. Na área estudada se encontra sobreposto a um aquitardo Mesozóico carbonático. Ambas as unidades, localmente, são interceptadas por um sistema de falhas nas direç̃es NE-SW e NW-SE. 0 objetivo do presente trabalho é o entendimento da interação entre a estruturação geológica da área e as variáveis hidrogeológicas e hidrogeoquímicas do aquífero Barreiras. As descontinuidades geradas pelas falhas propiciam caminhos de fluxo preferencial através dos quais ocorrem interações das águas subterrâneas do aquitardo e do aquífero, em profundidade por fluxo vertical ascendente. Corroborando, observa-se dois grupos distintos de águas em poços captando o aquífero Barreiras: Grupo 1, com fácies cloretada sódica, típica do aquífero Barreiras; Grupo 2, com fácies bicarbonatada cálcica a magnesiana, com influência do aquitardo carbonático.

Abstract

The Barreiras aquifer in the Boa Cica wells field, located in the Nísia Floresta Country/RN, is composed of siliciclastic rocks with a median thickness of 65 meters. The studied area it is over a Mesozoic carbonate aquitard. Both units, locally, are intercepted by fault system with NE-SW and NW-SE ditections. The objective of this study is to understand the interaction between the geological structuring of the area and the hydrogeological and hydrogeochemical variables. The faults yield discontinuities that causes a preferential flow path of groundwater interaction within the aquitard-aquifer, taking place in the depths by ascending vertical flow, This conclusion seems to be consistent with the fact that two distinct groups of groundwater have been observed: Group 1, of sodium-chloride type facies, typical of the Barreiras; Group 2, of calcium magnesium-bicarbonate type facies, typical of the carbonate aquitard.
\end{abstract}

DOI: http:/dx.doi.org/10.14295/ras.v33i1.29225

\section{INTRODUÇÃO}

O aquífero Barreiras, de natureza porosa, aflora paralelo a linha de costa brasileira desde o Estado do Rio de Janeiro até o Amapá (Figura 1A). Regionalmente, a sua potencialidade hídrica sob a ótica da produtividade dos poços é variável, e condicionada principalmente pela variação de espessura sedimentar, continuidade lateral e contexto climático. Na faixa costeira leste do Estado do Rio Grande do Norte, onde está inserida a área de estudo, Diniz, et al. (2014) destacam a relevância do aquífero no âmbito nacional, cujos poços apresentam alta produtividade (vazão $\geq 100 \mathrm{~m}^{3} / \mathrm{h}$ ) e fornecem águas de excelente qualidade. De fato, o aquífero Barreiras é o principal responsável pelo suprimento hídrico desse setor do Estado, incluindo a capital Natal e região metropolitana, e a sua importância ultrapassa o limite físico do aquífero Barreiras, pois suas águas são aduzidas através de um sistema de adutoras (Figura 1B), para setores geologicamente sob o domínio de rochas ígneas e metamórficas, onde se localizam municípios carentes em recursos hídricos situados no semiárido potiguar. 
Figura 1 - A) Área de estudo no contexto nacional e regional; B) Croqui esquemático de parte do sistema adutor Monsenhor Expedito; C) Geologia e estruturação da área; C') Estratigrafia simplificada (modificada de Lucena, 2005; Angelim et al., 2006 e Fonseca et al., 2012); D) Campo de poços da Boa Cica e localização dos pontos estudados
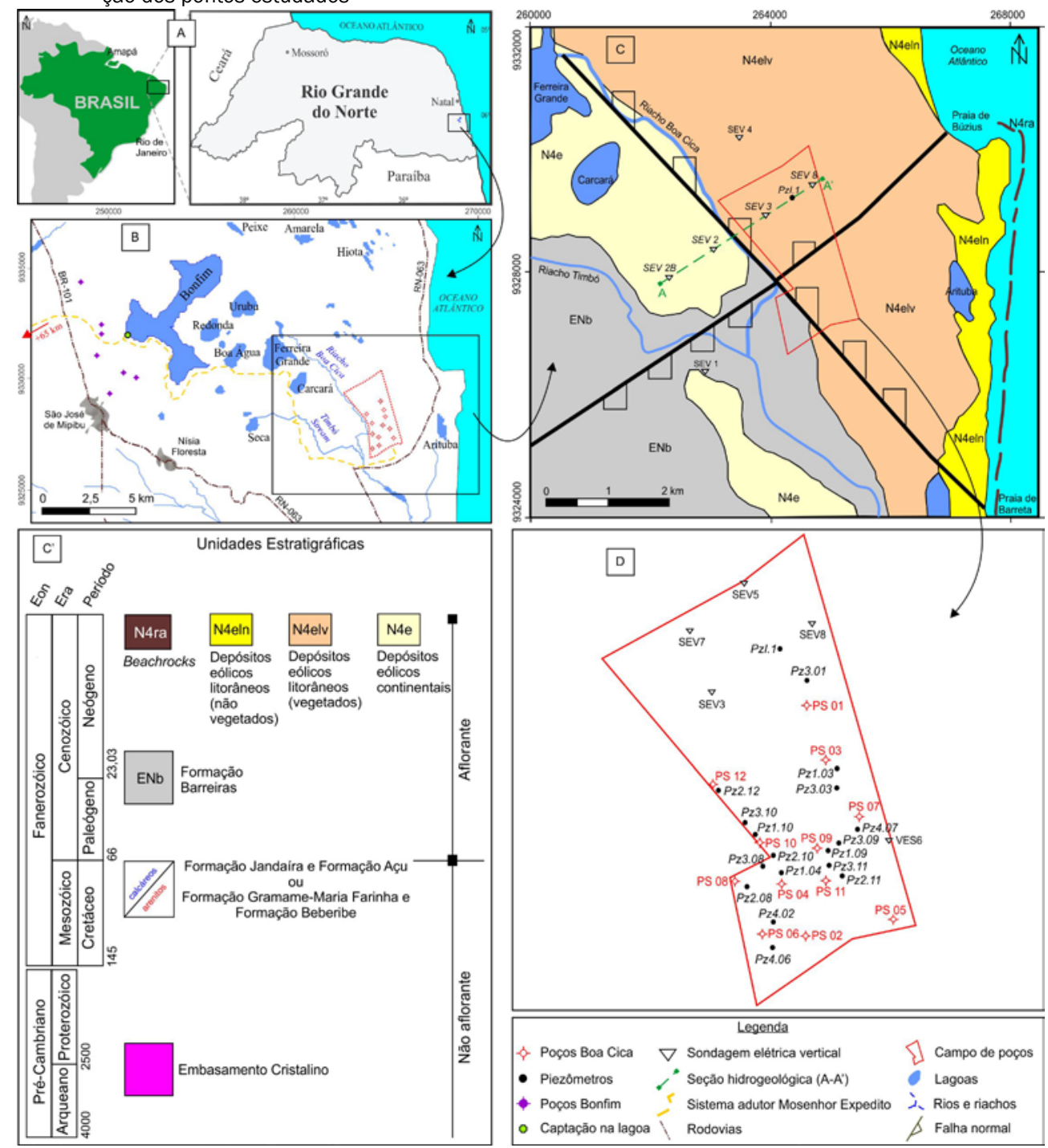

Trabalhos regionais apontam que as reservas hidrogeológicas do aquífero Barreiras no Estado do Rio Grande do Norte são condicionadas pela compartimentação estrutural do aquífero no local, a qual exerce influência no tamanho das espessuras saturadas, nas descontinuidade geológicas e, por conseguinte, no movimento e armazenamento da água subterrânea (Lucena, 2018)). Essa compartimentação é ocasionada pelo soerguimento ou rebaixamento do embasamento cristalino por ação das interferências dos sistemas de falhas (Lucena \& Queiroz, 1996; Lucena, 1999; Balsamo et al., 2010; Rodrigues et al., 2011 e Lucena et al, 2013). No entanto, inexistem pesquisas específicas que avaliam a influência estrutural no condicionamento das variáveis hidroquímicas do aquífero Barreiras. De acordo com Chihi et al (2015) sistema de falhamentos em aquíferos pode influenciar a geoquímica das águas subterrâneas de diversas formas, a exemplo quando diferentes litologias tornam-se contiguas e/ou a condutividade hidráulica próxima a falha vem a controlar o caminho do fluxo subterrâneo.

Nessa ótica, o principal objetivo desse estudo é estabelecer uma relação entre a influência da estruturação geológica e o comportamento hidroquímico do aquífero Barreiras na área de estudo. Para tanto, os resultados analíticos foram tratados estatisticamen-

te e agrupados visando a caracterização do padrão químico das águas. Buscou-se, também, avaliar se a compartimentação estrutural do aquífero em blocos condiciona a direção e velocidade do fluxo subterrâneo. A avaliação local desses componentes pode auxiliar num melhor entendimento do funcionamento hidráulico do aquífero Barreiras e sua associação com as diversas tipologias de água nos demais setores de ocorrência.

\section{2. ÁREA DE ESTUDO}

Os 12 poços tubulares investigados estão localizados no município de Nísia Floresta/RN e abastecem o Sistema Adutor Monsenhor Expedito (Figura 1B). Este sistema adutor é operado pela CAERN (Companhia de Águas e Esgotos do RN) desde 1997, distribuindo água para 30 municípios do RN, totalizando aproximadamente 290.000 habitantes abastecidos. Até 2015 o sistema operava com uma vazão de aproximadamente $1450 \mathrm{~m}^{3} / \mathrm{h}$, sendo $50 \%$ desse volume provenientes de sete poços tubulares (Poços Bonfim, na Figura 1B) no aquífero Barreiras e o restante da Lagoa do Bonfim (Captação, na Figura 1B), e aduzidas por $95 \mathrm{~km}$ até as regiōes abastecidas. Passados mais de 18 anos da instalação do sistema, o aumento na demanda de água impôs a necessidade de expandir o sistema de produção. Além disso, a captação do ma- 
nancial superficial (Lagoa do Bonfim) passou a ser conflito, tanto pelo uso da água em si, como por problemas ambientais decorrentes de um rebaixamento excessivo no nível da água da lagoa, especialmente em períodos de seca prolongada. Diante desse cenário, a SEMARH (Secretaria de Estado do Meio Ambiente e Recursos Hídricos do Rio Grande do Norte) promoveu a ampliação do sistema produtivo instalando uma bateria de 12 poços tubulares (Poços Boa Cica, nas Figuras 1B e 1D), localizada a aproximadamente $10 \mathrm{~km}$ da primeira bateria de sete poços. Para efeito, uma área de 421 hectares (Campo de poços, nas Figuras 1B, 1C e 1D), composta por vegetação preservada e distante da ocupação humana, foi desapropriada pelo governo estadual. A nova bateria, aqui denominada Campo de poços de Boa Cica, e objeto do pre- sente estudo, está em funcionamento desde 2015 e produz 750 $\mathrm{m}^{3} / \mathrm{h}$ de água.

\subsection{Precipitação Pluviométrica}

De acordo com dados históricos (1963-2007) da EMPARN - Empresa de Pesquisa Agropecuária do RN, obtidos do posto pluviométrico localizado no município de Nísia Floresta, o setor estudado apresenta precipitação média total anual de 1585,6 $\mathrm{mm}$. O período úmido (chuvoso) ocorre entre março e julho, com pico no mês de junho. Entre os meses de agosto e fevereiro ocorrem as menores precipitações, caracterizando o período de estiagem, sendo o mês de outubro o mais seco do ano (Figura 2).

Figura 2 - Precipitação pluviométrica média mensal (1963-2007) no município de Nísia Floresta/RN

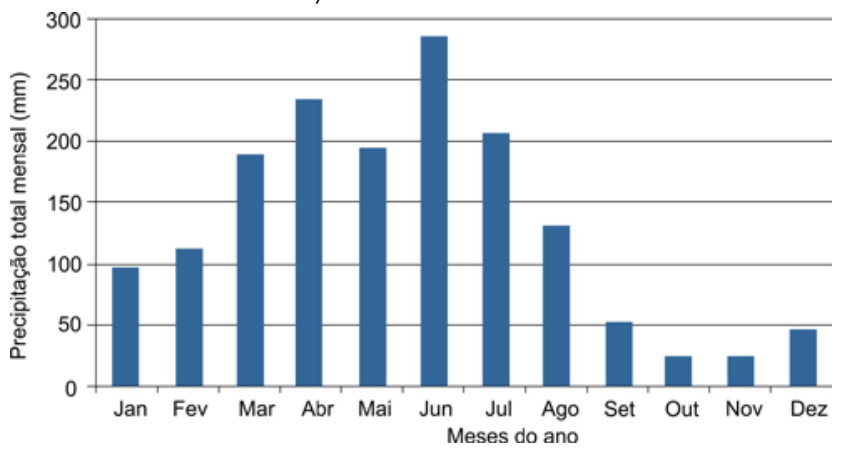

\subsection{Geologia}

A área de estudo está situada numa zona de transição entre as bacias sedimentares Potiguar e Paraíba, não sendo consenso entre autores se inserida plenamente na primeira ou na segunda. Encontra-se representada na área por duas sequências estratigráficas (Figura 1C'):

(i) Uma sequência inferior Mesozóica de idade Cretácica, não aflorante, assentada sobre o embasamento cristalino, composta por rochas sedimentares areníticas na base e carbonáticas no topo: Quando correlacionadas a Bacia Potiguar (Feitosa et al., 2002; Barbosa et al., 2007; Fonseca et al., 2012), a unidade arenítica é relacionada a Formação Açu e a unidade calcária à Formação Jandaíra, ambos inseridas no Grupo Apodi (Pessoa Neto et al. 2007). Quando correlacionadas a Bacia Paraíba, a unidade arenítica é pertencente à Formação Beberibe e a unidade carbonática à Formação GramameMaria Farinha, ambas inseridas no Grupo Paraíba (IPT, 1982, Rosseti et al., 2013).

(ii) Uma sequência superior Cenozóica de idade Paleogena a Neogena, aflorante, que consiste em depósitos clásticos continentais na base e eólicos no topo: A unidade continental é a Formação Barreiras, composta predominantemente por conglomerados a arenitos conglomeráticos e subordinadamente arenitos e argilitos, com aproximadamente $60 \mathrm{~m}$ de espessura (IPT, 1982). Essas rochas possuem coloração avermelhada, cimento ferruginoso e fraca diagênese. Podem apresentar horizontes e/ou colunas de oxi-redução que assumem cores variegadas (branca, vermelha e roxa). A referida Formação aflora no quadrante sudoeste da área, notadamente nas proximidades dos cursos de água. Sobreposto à essas rochas estão os pacotes sedimentares recentes (Neógenos) que compreendem: (1) Depósitos eólicos litorâneos nãovegetados que ocorrem paralelamente à linha de costa, compostos por areias quartzosas finas a médias de coloração esbranquiçada, na forma de dunas diversas (frontais, barcanóides, parabólicas). Esses pacotes em direção ao continente gradam para (2) Depósitos eólicos litorâneos vegetados compostos por areias quartzosas bem selecionadas de coloração avermelhada (películas de óxidos de ferro) a amarronzadas (matéria orgânica em decomposição). Na faixa oeste, os (3) Depósitos eólicos continentais recentes são constituídos de areias médias a finas derivadas de atividades eólicas, na forma de sedimentos espraiados, guardando a geometria de duna em alguns locais. Paralelamente à costa atual estão os (4) Beachrocks, distribuídos como linhas de recifes, compostos de arenitos com cimentação carbonática e bioclastos, de granulometria média a grossa.

\subsection{Contexto Estrutural}

O arcabouço tectono-estrutural regional da faixa litorânea leste do Estado do Rio Grande do Norte é caracterizado por falhas transcorrentes e normais com movimentos em duas direções preferenciais: NE-SW e NW-SE (Bezerra et al., 2001; Nogueira et al., 2006), possivelmente associados à deformação sin-sedimentar (Bezerra e Vita-Finzi, 2000). De acordo com Reis et al., (2013) o comportamento cinemático das falhas nas bacias sedimentares e no embasamento varia em termos de magnitude e direção: em profundidades mais rasas (inferiores a $2000 \mathrm{~m}$ ) predomina um regime de falhas normais e em maiores profundidades um regime de tensões transcorrentes. Considerando que a porção estudada está localizada a profundidades inferiores a $150 \mathrm{~m}$, predominam, portanto, os componentes verticais de caráter normal (rejeitos verticais), condicionadas a regime distensional. 
A Figura 1C sintetiza a estruturação da área de estudo, com a localização das falhas normais de direção NE-SW (Falha da Tabatinga) e NW-SE (Falha do Boa Cica). Estes sistemas de fraturas intercepta a Formação Barreiras em resposta a tectônica rúptil neógena (Nogueira et al., 2005; Rosseti et al., 2013), e é responsável pela geomorfologia do litoral leste potiguar, assim como pela a disposição dos depósitos sedimentares recentes no terreno (Lucena, 1999; Lucena, 2005; Andrades-filho et al., 2014).

A falha na direção NW-SE governa o alinhamento do Riacho Boa Cica na área de estudo e marca o limite sul-sudoeste do Graben Papary (Lucena e Queiroz, 1996; Lucena 2005). Essa proeminente estrutura possui assinatura em dados geofísicos profundos (gravimetria) e em escala de afloramento. Em profundidade, a referida estrutura está associada a um alinhamento gravimétrico definido por Lucena (2005) a partir da interpretação do campo gravimétrico residual. Movimentos neotectônicos rasos de idades entre aproximadamente 10.000 e 5.000 anos são relatados por Bezerra (1998) em beachrocks ao longo da localidade da Praia da Barreta onde a falha intercepta o litoral (Figura 1C).

\subsection{Contexto Hidrogeológico}

O aquífero Barreiras, inserido na formação homônima, segundo Melo (1995) forma juntamente com os depósitos eólicos sobrepostos, um sistema hidráulico único, denominado sistema aquífero Dunas-Barreiras, com espessura média da ordem de 60 metros. De fato, a permeabilidade das dunas favorece a recarga das águas subterrâneas a partir das chuvas. Trata-se de um aquífero livre, com semi-confinanentos localizados devido às intercalações argilosas que ocorrem na porção superior da Formação Barreiras. A transmissividade varia de $1,0 \times 10^{-3}$ a $3,0 \times 10^{-2} \mathrm{~m}^{2} / \mathrm{s}$ e a condutividade hidráulica de $1,9 \times 10^{-5}$ a $1,2 \times 10^{-3} \mathrm{~m} / \mathrm{s}$, e a porosidade específica é de aproximadamente 10\% (ANA, 2012; SEMARH, 2012a; SEMARH, 2012b). As águas do aquífero Barreiras no faixa costeira leste do Estado do Rio Grande do Norte são pouco mineralizadas (STD da ordem de $50 \mathrm{mg} / \mathrm{L}$ ), em razão da baixa solubilidade dos minerais constituintes das rochas armazenadoras, predominantemente quartzosos (Stein et al., 2012). A presença de poços com salinidade anômala, geralmente superior a $150 \mu \mathrm{S} / \mathrm{cm}$, é relacionada a contaminação das águas, notadamente associados ao íon nitrato em ambiente urbano (Cabral et al., 2009).

Subjacente, o embasamento hidrogeológico do aquífero Barreiras é constituído por uma sequência carbonática Mesozóica, com característica de aquitardo e permeabilidade associada a fraturas produzidas pela reativação Neógena de antigas falhas (SERHID,1998a). Apesar da baixa produtividade hídrica, informações verbais de perfuradores apontam um crescente aumento no número de poços captando essa unidade, sobretudo em áreas urbanas onde o aquífero Barreiras já apresenta águas contaminadas com nitrato (SERHID, 1998b).

\section{MATERIAIS E MÉTODOS}

\subsection{Hidrogeologia e Geofísica}

Na pesquisa foram considerados os dados de 12 poços tubulares (PS) totalmente penetrantes no aquífero Barreiras, 18 piezômetros $(\mathrm{Pz})$ e 09 sondagens elétricas verticais (SEV), apresentados na Figura 1C e 1D e Tabela 1. As perfurações foram realizadas pelo método percussivo, com coleta de amostras de calha a cada metro perfurado para definição do perfil litológico. A determinação do nível da água nos poços e piezômetros foi realizada com medidor elétrico de nível e o levantamento topográfico com equipamento de GPS geodésico. Na elaboração do mapa de fluxo de água subterrânea na área de estudo, foram utilizados apenas os dados dos poços, adotando a krigagem como método de interpolação de dados e o software Golden Surfer 9 na confecção.

Tabela 1 - Sumário estatístico dos dados hidrogeológicos

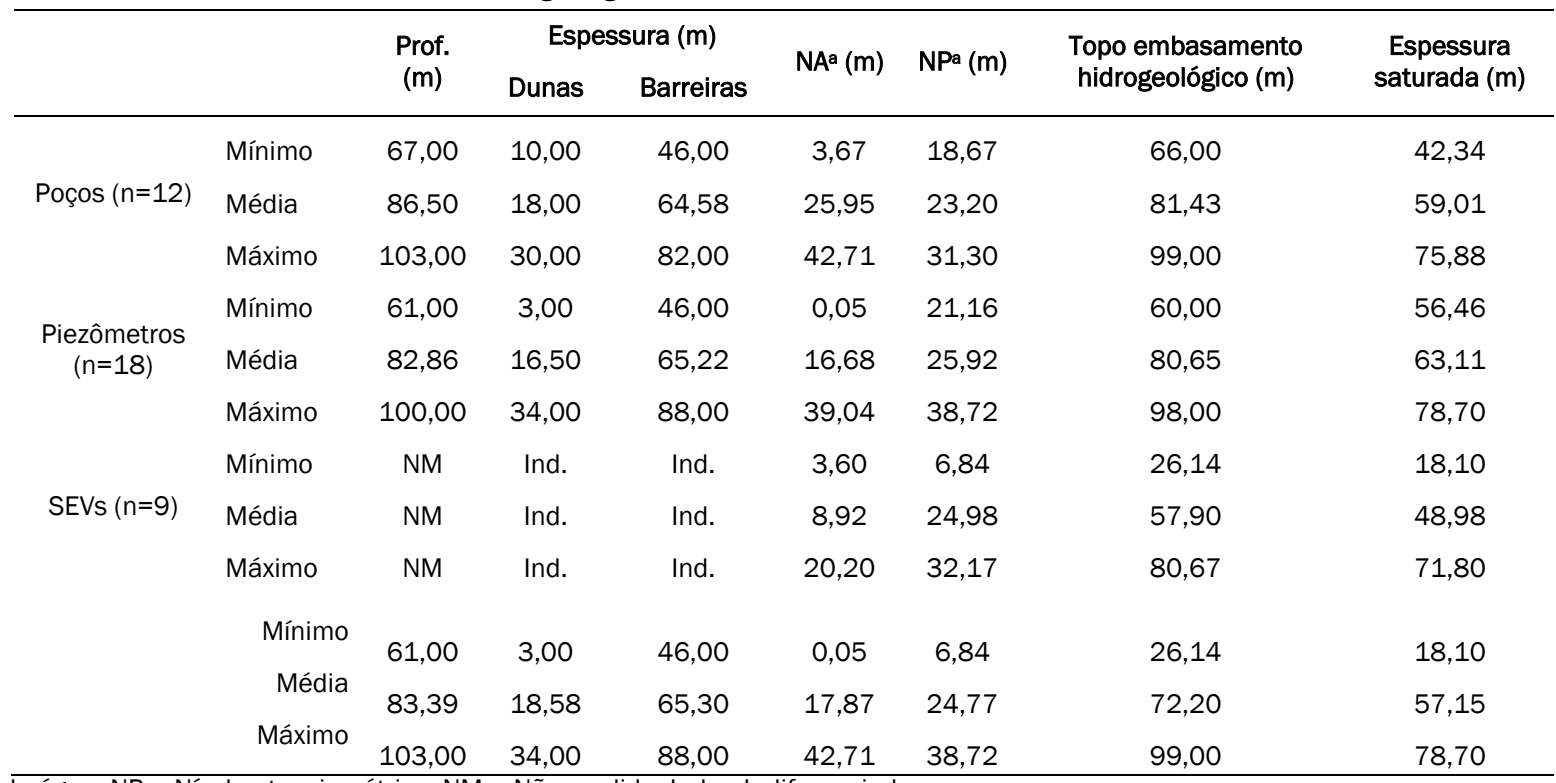

NA = Nivel da água. NP = Nível potenciométrico. NM = Não medido. Ind. = Indiferenciado.

a) Data das medições: Poços em janeiro de 2013. Piezômetros de dezembro de 2011 a fevereiro de 2012 . SEVs em janeiro de 2014.

A eletrorresistividade aplicada à pesquisa de águas subterrâneas (Kirsch, 2006; Feitosa et al., 2008) supriu de informações as áreas sem cobertura de poços e piezômetros e foi realizada no intuito de mapear a espessura do aquífero Barreiras, bem como, localizar as descontinuidades (fraturas e falhas) existentes. No levantamento utilizou-se o arranjo de eletrodos Schlumberger 
(Orellana, 1972) com aberturas máximas de corrente de 1,2 km $(\mathrm{AB} / 2=600 \mathrm{~m})$. Os dados de campo em termos de resistividade aparente e $A B / 2$ possibilitam então a elaboração de modelos de resistividade $x$ espessura mediante inversão geolétrica (Medeiros e Silva, 1996), calibrados com base em Lucena (2005). Da integração dos resultados, um perfil hidrogeofísico elaborado no CoreIDRAW X5 subsidiou a caracterização das falhas locais, especialmente a do Riacho Boa Cica, bem como mapas de espessura total e saturada do aquífero Barreiras.

\subsection{Hidrogeoquímica}

Os poços foram amostrados em duas campanhas (julho de 2012 e março de 2014), ambas representativas do período chuvoso (final e início da estação úmida, respectivamente) (Figura 2). Por questões operacionais não foi possível a amostragem de águas na época seca. Um total de 24 amostras de águas (Tabela 2) foi coletada através de bombeamento com bomba submersa, após uma purga prévia dos poços por aproximadamente 30 minutos para evitar a coleta da água estagnada. No Riacho Boa Cica foi realizada apenas uma campanha amostral, em março de 2014, em dois pontos do rio (duas amostras). Ambas as campanhas realizadas antes da implantação do sistema de adução de água. Os procedimentos de armazenamento e preservação seguiram as recomendações do Standard Methods for the Examination of Water \& Wastewater (APHA, 2005).

$\mathrm{O}$ pH e os parâmetros de salinidade (condutividade elétrica e sólidos totais dissolvidos) foram medidos in situ utilizando uma sonda multiparâmetro. As análises dos cátions $\mathrm{Ca}^{2+}{\mathrm{e} \mathrm{Mg}^{2+}}^{2+}$ foram realizadas através do método volumétrico de EDTA e dos cátions $\mathrm{Na}^{+}$e $\mathrm{K}^{+}$por fotometria de chama. O limite de detecção analítica dos cátions foi de $0,1 \mathrm{mg} / \mathrm{L}$. A dureza total foi calculada a

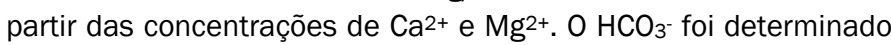
por cálculo através do resultado da alcalinidade realizada em laboratório por titulação potenciométrica. A análise do ânion $\mathrm{SO}_{4}{ }^{2}$ foi realizada pelo método turbidimétrico e a do $\mathrm{Cl}$ - pelo volumétrico de nitrato de prata, com limite de detecção de 1,0 e $1,5 \mathrm{mg} / \mathrm{L}$, respectivamente. Os compostos da série nitrogenada determinados pelo método colorimétrico, com limite de detecção de 0,04 , 0,01 e 0,02 mg/L para o $\mathrm{NO}_{3}^{-}, \mathrm{NO}_{2}^{-}$e $\mathrm{NH}_{3}$, respectivamente. $\mathrm{Na}$ determinação dos índices de saturação (IS) da dolomita e calcita foi utilizado o pacote PHREEQC v.3.0 (Parkhurst and Appelo, 2013).

A avaliação da qualidade dos dados analíticos foi feita mediante o cálculo do balanço iônico, considerando-se um erro inferior a 5\% como aceitável (Custódio \& Llamas, 1983). No tratamento dos resultados hidroquímicos utilizou-se o software AquaChem v.5.1, que possibilitou a caracterização de fácies das águas analisadas, através das representações nos diagramas de Piper, Stiff, Schoeller e Gibbs. A análise estatística e demais gráficos foram elaborados com o software Excel.

\section{RESULTADOS E DISCUSSÕES}

\subsection{Condicionamento estrutural}

Os modelos inversos obtidos da interpretação das sondagens geoelétricas integralizados com os perfis litológicos dos poços e piezômetros mostram que o topo do pacote carbonático, que constitui o embasamento hidrogeológico do aquífero Barreiras na área da Boa Cica, está entre 26 e 99 metros de profundidade (Tabela 1 e Figura 3A). Essa profundidade, que pode ser considerada também como a espessura total do aquífero Barreiras no trecho avaliado, de um modo geral, decresce de leste para oeste. A espessura saturada (Figura 3B) apresenta padrão de distribuição semelhante à espessura total do aquífero, neste caso variando de 18 e 79 metros (Tabela 1).

Figura 3 - Condicionamento estrutural. A) Topo da sequência de carbonática mesozóica (m) (embasamento hidrogeológico). B) Espessura saturada (m) do aquífero Barreiras. Base estrutural modificada de Lucena, 2005; Angelim et al., 2006 e Fonseca et al., 2012)

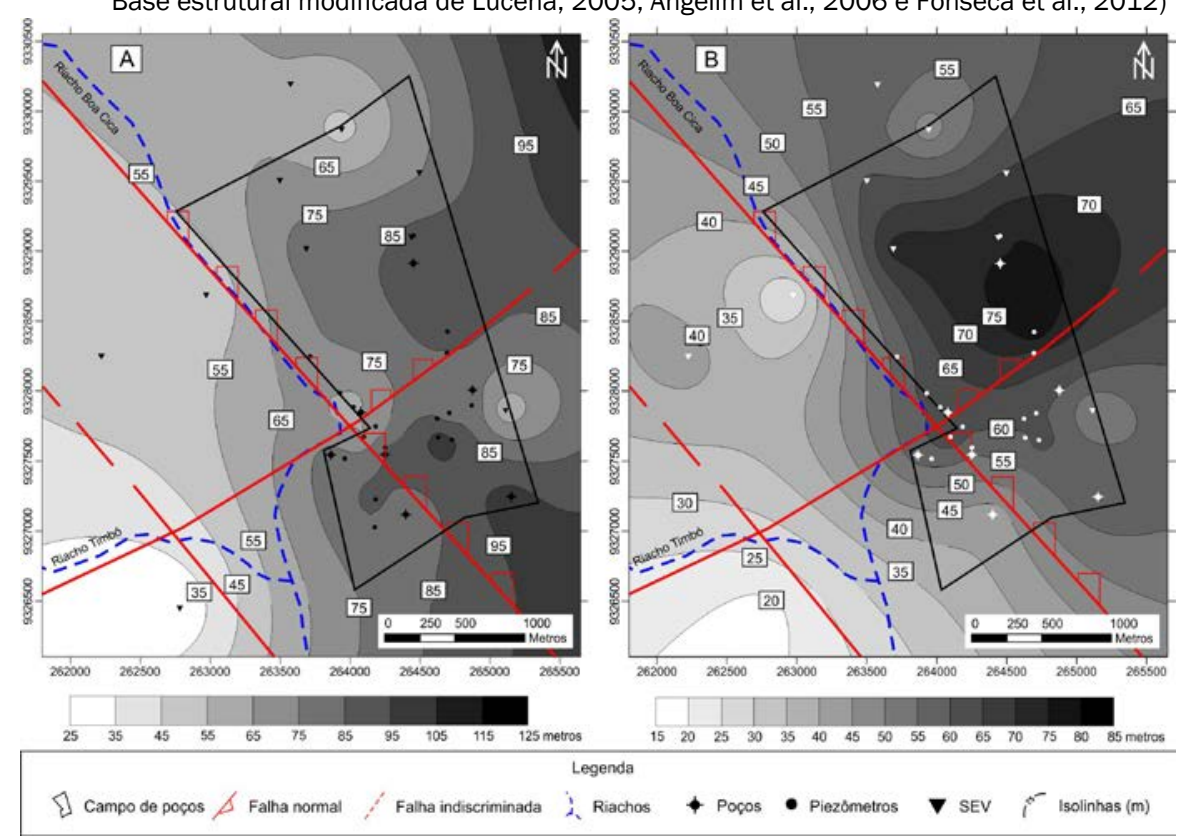


Tabela 2 -Parâmetros físico-químicos das águas subterrâneas e superficiais (Riacho Boa Cica)

\begin{tabular}{|c|c|c|c|c|c|c|c|c|c|c|c|c|c|c|c|c|c|}
\hline Ponto & $\begin{array}{l}\text { Data amostra- } \\
\text { gem }\end{array}$ & $\mathrm{pH}^{\mathrm{a}}$ & $\begin{array}{l}\mathrm{CE} \\
(\mu \mathrm{S} / \mathrm{cm})^{\mathrm{a}}\end{array}$ & $\begin{array}{l}\text { STD } \\
(\mathrm{mg} / \mathrm{L})^{\mathrm{a}}\end{array}$ & $\begin{array}{l}\mathrm{DT}(\mathrm{mg} / \mathrm{L} \\
\left.\mathrm{CaCO}_{3}\right)\end{array}$ & $\begin{array}{l}\mathrm{Ca}^{2+} \\
(\mathrm{mg} / \mathrm{L})\end{array}$ & $\begin{array}{l}\mathrm{Mg}^{2+} \\
(\mathrm{mg} / \mathrm{L})\end{array}$ & $\begin{array}{l}\mathrm{Na}^{+} \\
(\mathrm{mg} / \mathrm{L})\end{array}$ & $\begin{array}{l}\mathrm{K}^{+} \\
(\mathrm{mg} / \mathrm{L})\end{array}$ & $\begin{array}{l}\mathrm{HCO}_{3}^{-} \\
(\mathrm{mg} / \mathrm{L})\end{array}$ & $\begin{array}{l}\mathrm{SO}_{4}^{2-} \\
(\mathrm{mg} / \mathrm{L})\end{array}$ & $\begin{array}{l}\mathrm{Cl}^{-} \\
(\mathrm{mg} / \mathrm{L})\end{array}$ & $\begin{array}{l}\mathrm{NO}_{3}-(\mathrm{mg} / \mathrm{L} \\
\mathrm{N})\end{array}$ & $\begin{array}{l}\mathrm{NO}_{2}^{-} \\
(\mathrm{mg} / \mathrm{L} \mathrm{N})\end{array}$ & $\begin{array}{l}\mathrm{NH}_{3} \\
(\mathrm{mg} / \mathrm{L})\end{array}$ & IS Dolomita & Is Calcita \\
\hline \multirow{2}{*}{ PS 01} & Julho, 2012 & 6,50 & 45,80 & 39,14 & 5,12 & 5,47 & 2,79 & 12,90 & 2,33 & 0,30 & 0,92 & 21,24 & 0,31 & $<\mathrm{LD}$ & 0,17 & $-9,31$ & $-4,65$ \\
\hline & Março, 2014 & 6,10 & 47,82 & 32,51 & 5,60 & 0,41 & 1,13 & 8,33 & 0,57 & 1,20 & 5,60 & 13,25 & 0,97 & $<L D$ & 0,15 & $-10,41$ & $-5,57$ \\
\hline \multirow{2}{*}{ PS 02} & Julho, 2012 & 6,50 & 77,60 & 52,76 & 24,64 & 4,93 & 2,99 & 13,57 & 0,74 & 29,61 & 3,13 & 19,61 & 0,84 & $<L D$ & $<\mathrm{LD}$ & $-5,41$ & $-2,74$ \\
\hline & Março, 2014 & 6,20 & 52,95 & 36,00 & 7,64 & 1,45 & 1,00 & 7,77 & 0,57 & 3,59 & 5,79 & 11,60 & 1,99 & $<L D$ & 0,16 & $-8,80$ & $-4,46$ \\
\hline \multirow{2}{*}{ PS 03} & Julho, 2012 & 7,30 & 96,20 & 65,41 & 18,69 & 4,93 & 1,55 & 14,94 & 0,61 & 29,61 & 1,65 & 19,61 & 0,22 & $<L D$ & $<L D$ & $-4,09$ & $-1,94$ \\
\hline & Março, 2014 & 6,60 & 46,87 & 31,87 & 7,64 & 1,24 & 1,13 & 7,77 & 0,57 & 3,59 & 5,91 & 13,25 & $<L D$ & $<L D$ & 0,12 & $-8,01$ & $-4,13$ \\
\hline \multirow{2}{*}{ PS 04} & Julho, 2012 & 6,70 & 114,80 & 52,00 & 36,53 & 9,69 & 2,99 & 13,57 & 2,96 & 36,72 & 1,29 & 26,14 & $<\mathrm{LD}$ & $<L D$ & $<L D$ & $-4,55$ & $-2,16$ \\
\hline & Março, 2014 & 6,90 & 63,16 & 42,95 & 14,78 & 2,27 & 2,26 & 7,77 & 2,00 & 11,96 & 5,92 & 13,25 & $<\mathrm{LD}$ & $<\mathrm{LD}$ & 0,18 & $-5,83$ & $-3,05$ \\
\hline \multirow{2}{*}{ PS 05} & Julho, 2012 & 6,60 & 47,30 & 32,16 & 5,10 & 0,51 & 0,93 & 7,74 & 1,00 & 9,47 & 0,74 & 11,44 & $<L D$ & $<L D$ & $<L D$ & $-7,62$ & $-4,08$ \\
\hline & Março, 2014 & 6,10 & 44,25 & 30,00 & 4,59 & 0,83 & 0,63 & 7,77 & 0,85 & 1,20 & 5,80 & 13,25 & $<\mathrm{LD}$ & $<L D$ & 0,12 & $-10,35$ & $-5,26$ \\
\hline \multirow{2}{*}{ PS 06} & Julho, 2012 & 6,80 & 92,60 & 62,97 & 19,53 & 3,91 & 2,37 & 15,00 & 1,07 & 20,13 & 7,17 & 19,61 & 2,17 & $<L D$ & $<\mathrm{LD}$ & $-5,35$ & $-2,71$ \\
\hline & Março, 2014 & 6,50 & 59,86 & 40,70 & 15,29 & 2,45 & 2,23 & 8,00 & 2,50 & 7,17 & 4,00 & 19,88 & 1,86 & $<L D$ & 0,07 & $-7,05$ & $-3,64$ \\
\hline \multirow{2}{*}{ PS 07} & Julho, 2012 & 5,90 & 42,50 & 28,90 & 5,52 & 0,51 & 1,03 & 8,38 & 0,33 & 5,92 & 0,74 & 13,07 & $<L D$ & $<L D$ & $<\mathrm{LD}$ & $-9,38$ & $-4,98$ \\
\hline & Março, 2014 & 6,30 & 42,61 & 28,98 & 7,14 & 1,22 & 0,99 & 9,14 & 0,50 & 4,78 & 3,63 & 16,57 & $<L D$ & $<L D$ & $<\mathrm{LD}$ & $-8,43$ & $-4,31$ \\
\hline \multirow{2}{*}{ PS 08} & Julho, 2012 & 7,90 & 223,00 & 151,64 & 78,15 & 18,03 & 8,05 & 10,63 & 5,31 & 106,59 & 1,10 & 16,34 & 0,75 & $<L D$ & $<\mathrm{LD}$ & $-0,61$ & $-0,27$ \\
\hline & Março, 2014 & 7,90 & 210,50 & 143,14 & 87,66 & 18,37 & 10,15 & 9,14 & 5,43 & 96,88 & 6,60 & 18,88 & 1,73 & $<L D$ & $<L D$ & $-0,60$ & $-0,31$ \\
\hline \multirow{2}{*}{ PS 09} & Julho, 2012 & 6,70 & 62,50 & 42,50 & 17,84 & 5,61 & 0,93 & 7,74 & $<\mathrm{LD}$ & 17,77 & 0,74 & 14,70 & $<\mathrm{LD}$ & $<L D$ & $<\mathrm{LD}$ & $-5,87$ & $-2,69$ \\
\hline & Março, 2014 & 6,00 & 43,85 & 29,87 & 6,11 & 0,82 & 0,99 & 7,43 & 0,50 & 3,58 & 3,83 & 13,25 & 1,24 & $<L D$ & $<\mathrm{LD}$ & $-9,43$ & $-4,90$ \\
\hline \multirow{2}{*}{ PS 10} & Julho, 2012 & 7,80 & 245,00 & 166,60 & 87,49 & 17,86 & 10,42 & 11,61 & 6,00 & 117,88 & 1,85 & 22,87 & 0,31 & $<L D$ & $<\mathrm{LD}$ & $-0,63$ & $-0,34$ \\
\hline & Março, 2014 & 8,00 & 195,96 & 133,25 & 83,58 & 17,14 & 9,90 & 10,28 & 5,14 & 88,51 & 4,28 & 23,19 & 1,20 & 0,20 & $<\mathrm{LD}$ & $-0,51$ & $-0,28$ \\
\hline \multirow{2}{*}{ PS 11} & Julho, 2012 & 5,90 & 48,00 & 32,64 & 7,64 & 2,55 & 0,31 & 7,10 & 0,67 & 5,92 & 0,56 & 13,07 & $<\mathrm{LD}$ & $<L D$ & 0,02 & $-9,20$ & $-4,28$ \\
\hline & Março, 2014 & 5,90 & 41,89 & 28,48 & 6,12 & 0,82 & 0,99 & 8,00 & 0,28 & 3,58 & 2,93 & 13,25 & 1,59 & $<\mathrm{LD}$ & $<\mathrm{LD}$ & $-9,63$ & $-5,00$ \\
\hline \multirow{2}{*}{ PS 12} & Julho, 2012 & 7,20 & 151,10 & 102,74 & 59,76 & 12,07 & 7,12 & 10,97 & 3,67 & 73,43 & 0,56 & 16,34 & 0,80 & $<L D$ & $<L D$ & $-2,51$ & $-1,28$ \\
\hline & Março, 2014 & 7,20 & 106,45 & 72,38 & 36,69 & 6,94 & 4,70 & 8,57 & 2,28 & 37,08 & 5,36 & 16,57 & 1,33 & $<L D$ & $<\mathrm{LD}$ & $-3,49$ & $-1,80$ \\
\hline Rio 1 & Março, 2014 & 6,50 & 52,32 & 35,57 & 6,12 & 1,22 & 0,74 & 10,28 & 1,14 & 10,76 & 2,76 & 13,25 & 1,33 & $<L D$ & $<\mathrm{LD}$ & $-7,46$ & $-3,76$ \\
\hline Rio 2 & Março, 2014 & 6,70 & 62,40 & 42,43 & 13,25 & 2,04 & 1,98 & 8,00 & 1,71 & 11,96 & 6,02 & 13,25 & 1,59 & $<\mathrm{LD}$ & 0,06 & $-6,33$ & $-3,30$ \\
\hline
\end{tabular}

CE: Condutividade elétrica. STD: Sólidos totais dissolvidos. DT: Dureza total. IS: Índice de saturação. LD: Limite de detecção 
A variabilidade dos resultados reflete a compartimentação estrutural do reservatório, decorrente principalmente da falha que marca o Riacho Boa Cica (direção NW-SE) que, via de regra, condiciona a área em: a leste do falhamento (embasamento hidrogeológico mais profundo) e a oeste do falhamento (embasamento hidrogeológico mais raso). Secundariamente, o falhamento de direção NESW (Falha da Tabatinga) também exerce controle nas espessuras, sobretudo no extremo sudoeste da área (espessuras total e saturada inferiores a 45 e 25 metros, respectivamente) e porção nordeste (espessura saturada superior a $75 \mathrm{~m}$ ). Essa compartimentação é caracterizada por abatimentos e soerguimentos relativos do topo do embasamento hidrogeológico local, já que ambos os sistemas de falhas apresentam caráter profundo na crosta (Lucena, 2005). Superficialmente observa-se a inflexão no curso da água do Riacho Boa Cica em resposta o truncamento desses dois falhamentos principais.
Na seção hidrogeofísica apresentada na Figura 4, que interceptatransversalmente o Riacho Boa Cica (localização da seção na Figura $1 \mathrm{C}$ ), pode-se visualizar a variação na profundidade do embasamento hidrogeológico, marcadas pelos falhamentos, sobretudo o do Riacho Boa Cica, onde é possível quantificar um rejeito da ordem de 25 metros. A esquerda do rio os dados geoelétricos da VES2B e VES2 apontam cotas altimétricas de -13,4 e -17,76m, respectivamente, para o topo do pacote carbonático. Provavelmente essa variação de 4,2 metros tenha uma natureza puramente topográfica ou relacionada a uma superfície erosiva no topo da sequência carbonática, e, portanto, não pode ser correlacionada a um rejeito de falha. No setor da faixa a direita ao rio, à nordeste da falha do Boa Cica, a cota do topo do embasamento hidrogeológico está a -42,6 e -37,2 metros, respectivamente, na VES3 e VES8. No piezômetro Pzl.1 é superior a -48 metros (já que o topo do embasamento não foi interceptado), e provavelmente decorre de falhas secundárias paralelas associadas a falha principal do Boa Cica.

Figura 4 - Seção hidrogeofísica transversal de direção SW-NE, interceptando a falha da Boa Cica. Ver a Figura 1C para localização

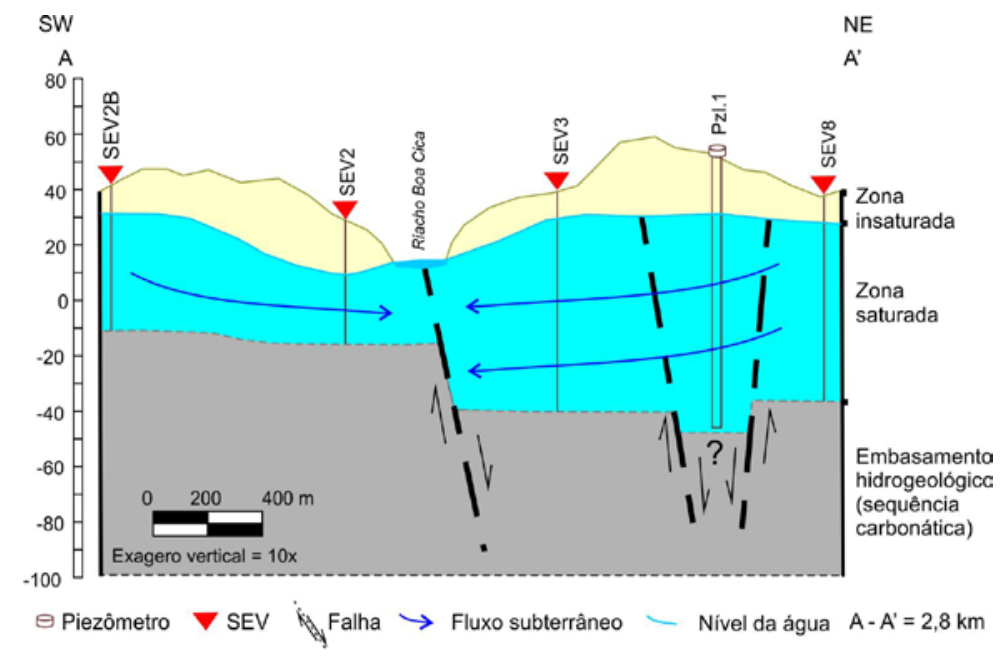

\subsection{Fluxo Subterrâneo}

0 aquífero Barreiras tem recarga direta das chuvas, que se infiltram a partir da superfície do terreno, composta por depósitos eólicos (dunas), e se armazenam na porção inferior do pacote siliciclástico (Formação Barreiras) delimitado pelo topo do embasamento hidrogeológico carbonático. As dunas, na área de estudo, permanecem insaturadas, funcionando apenas como condutor hidráulico.

O fluxo de águas subterrâneas é baseado no mapa potenciométrico da Figura 5, elaborado com os dados de nível da água nos poços em janeiro de 2013 (início da estação chuvosa). A direção geral do fluxo hídrico é para o sudoeste, no sentido do Riacho Boa Cica. As estruturas tectônicas, localmente, parecem exercer um leve controle no condicionamento do percurso do fluxo subterrâneo, na medida em que os dois sistemas de falhas (NW-SE e NESW) que interceptam a área, ao se truncarem, são responsáveis por inflexões sutis na direção do escoamento subterrâneo, indicado pelas setas na figura. No âmbito regional, a área de estudo localiza-se em um setor de descarga do aquífero Barreiras, conforme evidenciado pelas equipotenciais o caráter influente do aquífero no setor pesquisado.

\subsection{Hidrogeoquímica}

\subsubsection{Fácies Hidroquímicas e Grupos de Águas}

A avaliação da composição da água subterrânea com base na concentração dos cátions e ânions dominantes permitiu a individualização das fácies hidroquímicas que caracterizam distintos tipos de águas, bem como, a identificação de processos hidrogeoquímicos que determinam sua evolução. Para tanto foram utilizados diagramas de Piper (Piper, 1944), Schoeller (Schoeller, 1935) e Stiff (Stiff, 1951), que indicaram a ocorrência de dois grupos principais de águas em ambos os períodos amostrais (Figura 6A):

- Águas cloretadas sódicas, Grupo 1: Poços PS 01, PS 02, PS 03, PS 04, PS 05, PS 06, PS 07, PS 09 e PS 11 e e as águas do Riacho Boa Cica;

- Águas bicarbonatadas cálcico-magnesianas, Grupo 2: Poços PS 08, PS 10, PS 12.

Na Figura 6B o diagrama de Schoeller ratifica a distinção entre os grupos, em função das concentrações superiores dos íons $\mathrm{Ca}^{2+}$, $\mathrm{Mg}^{2+}$ e $\mathrm{HCO}_{3}-$ no Grupo 2, em relação ao Grupo 1. 
A presença de águas bicarbonatadas e cloretadas no aquífero Barreiras em Natal/RN é relatada por Melo (1995) e relacionada com a evolução do fluxo subterrâneo; respectivamente à águas mais rasas (de fluxo local) e à águas mais profundas (de fluxo regional). De fato, Drever (1998) e Appelo e Postma (2005) enfatizam mudanças hidroquímicas ao longo do fluxo de águas subterrâneas, onde as bicarbonatadas cálcicas são características de zonas de recarga e evoluem para águas cloretadas sódicas nas zonas de descarga. Dado o contexto espacialmente limitado (reduzido) da área de estudo, a possibilidade de modificações hidroquímicas em função da evolução ao longo do fluxo é bastante reduzida. Os poços do Grupo 2 (águas bicarbonatadas cálcicomagnesianas) estão localizados próximos ao sistema de falhamen- tos NE-SW e NW-SE (Figura 7) e considerando que tais estruturas adentram o embasamento hidrogeológico de natureza calcífera, é provável que localmente ocorra a mistura de águas entre ambas as unidades (aquífero Barreiras sobrejacente e aquitardo carbonático subjacente), produzida pela presença de fluxo vertical ascendente ao longo das falhas, processo que não ocorre nas águas do Grupo 1 (águas cloretadas sódicas). Não fica descartada, também, a hipótese que o truncamento do fluxo subterrâneo no aquífero Barreiras, em função da descontinuidade estrutural (Figura 4), propicie localmente um maior tempo de interação água-rocha nesse domínio, que se reflete na dissolução do maciço carbonático.

Figura 5 - Potenciometria do aquífero Barreiras na

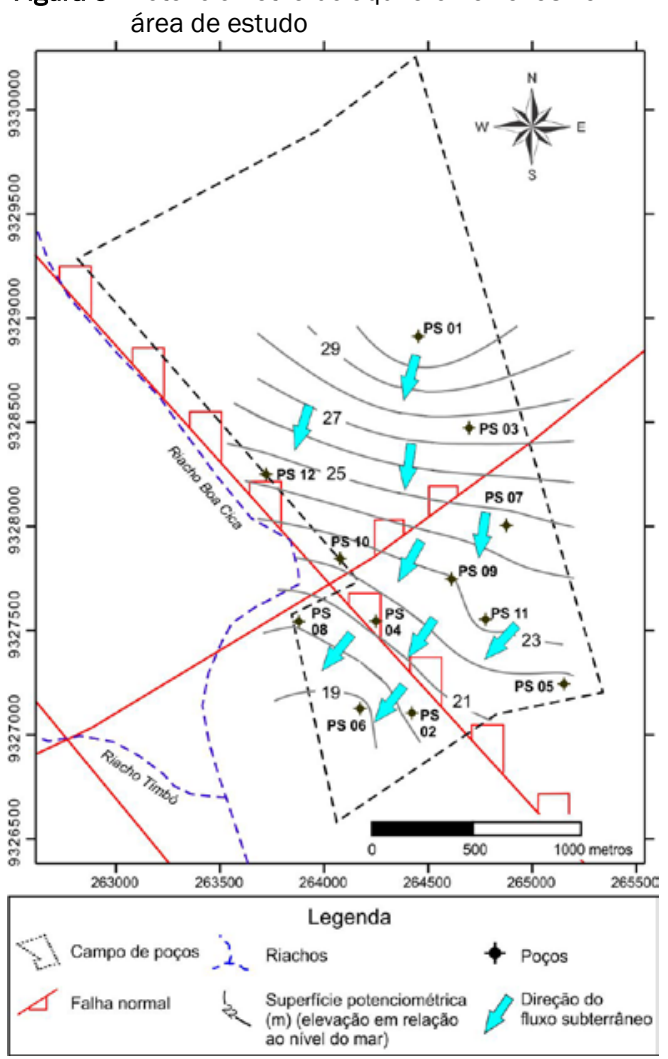

Figura 6 - Diagramas das amostras de águas subterrâneas e superficiais. A) Diagrama de Piper; B) Diagrama de Schoeller
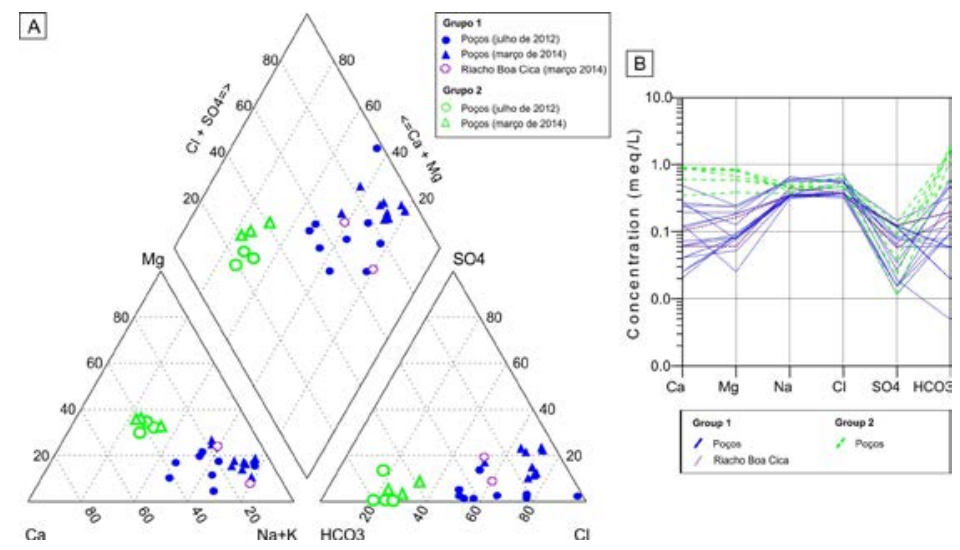
A fácies cloretada sódica predomina regionalmente no aquífero Barreiras do litoral oriental do Rio Grande do Norte (IPT, 1982). No âmbito estudado ela está contemplada nas águas do Grupo 1. Nessa fácie a predominância dos íons $\mathrm{Na}^{+}$e $\mathrm{Cl}$ - deve-se possivelmente a água de recarga, oriundas das chuvas carregadas de aerossóis marinhos, já que a área estudada se localiza próximo à linha de costa. Outro aspecto a ser considerado é o arcabouço litológico do aquífero, composto predominantemente por arenitos quartzosos, o que acarreta em poucos elementos disponíveis para a dissolução mineral, e consequentemente no reduzido conteúdo iônico dessas águas, conforme se pode visualizar na configuração dos diagramas de Stiff da Figura 7.
Estudos regionais apontam a descarga das águas subterrâneas em direção às principais drenagens (SEMARH, 1998). Essa configuração é comprovada localmente na área de estudo (Figura 5), e corroborada pela similaridade hidroquímica observada entre as águas subterrâneas do Grupo 1 e as amostras de águas superficiais.

De maneira geral, a maior concentração de cada íon analisado se dá na amostragem realizada em julho de 2012, o que pode ser verificado através dos diagramas de Stiff da Figura 7, notadamente paras as águas do Grupo 1.

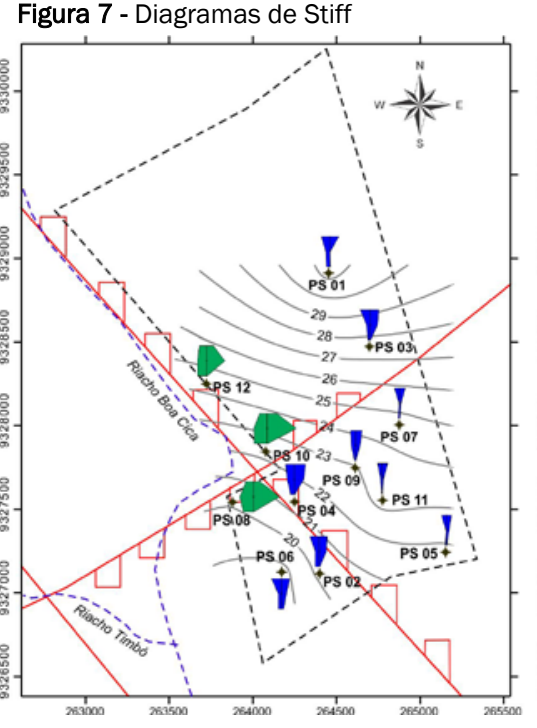

\subsubsection{Análise estatística}

Na Figura 8 os resultados estatísticos das amostras agrupadas são ilustrados em diagramas boxplots. No Grupo $10 \mathrm{pH}$ apresentou um valor médio de 6,54 na coleta de julho de 2012 e 6,29 em março de 2014; portanto tendendo a águas levemente ácidas. Águas ácidas são típicas do aquífero Barreiras, devido a sua recarga rápida e direta das chuvas. Aquíferos porosos, onde o arcabouço é predominantemente siliciclástico, tendem a apresentarem esse tipo de águas, já que a litologia não favorece o aumento da alcalinidade necessária para neutralizar o pH das águas (Domenico \& Schwartz, 1990; Drever, 2002). São águas brandas (classificação baseada em Custódio e Llamas, 1983), com dureza máxima

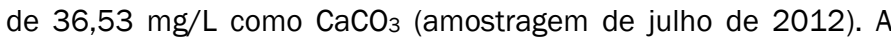
salinidade, observada através do parâmetro STD, evidenciou águas doces (classificação de Mcneely et al., 1979), cujo a média ficou entre 45,39 (amostragem de julho de 2012) e 33,49 mg/L (no período de março de 2014). Os teores dos componentes químicos em ordem de predominância foram para os cátions e os ânions, respectivamente, nas duas etapas de amostragem de $\mathrm{Na}^{+}$ $>\mathrm{Ca}^{2+}>\mathrm{Mg}^{2+}>\mathrm{K}^{+}$e $\mathrm{Cl}^{-}>\mathrm{HCO}^{3-}>\mathrm{SO}_{4}{ }^{2-}$. Nota-se, portanto, que as águas do Grupo 1, comportam-se como um sistema quimicamente aberto, onde sua composição é diretamente influenciada pelas precipitações pluviométricas. No que se refere aos compostos nitrogenados $\mathrm{O} \mathrm{NO}_{3}$ - apresentou teor máximo $2,17 \mathrm{mg} / \mathrm{L} \mathrm{N}$ (PS 06) na amostragem de julho de 2012. Os demais compostos nitrogenados não foram tratados na estatística porque predominaram os resultados abaixo do LD (Tabela 2 ).

No Grupo 2 o pH médio foi de 7,63 na amostragem de julho de 2012 e 7,7 em março de 20014, caracterizando águas levemente alcalinas. As águas são definidas como doces (STD médio variando de 140,33 em julho de 2012 e 116,26 mg/L em março de 20014), tal como evidenciado para o Grupo 1, entretanto registrando concentrações superiores. A dureza variou entre 36,69 a $87,66 \mathrm{mg} / \mathrm{L}$ como $\mathrm{CaCO}_{3}$, ambos registrados na amostragem de março de 2012, portanto abarcando águas brandas ( $<50 \mathrm{mg} / \mathrm{L})$ a pouco duras (entre 50 e $100 \mathrm{mg} / \mathrm{L}$ ). 0 predomínio de cátions e ânions foi de $\mathrm{Ca}^{2+}>\mathrm{Na}^{+}>\mathrm{Mg}^{2+}>\mathrm{K}^{+}$e $\mathrm{HCO}_{3-}>\mathrm{Cl}^{-}>\mathrm{SO}_{4}{ }^{2-}$, respectivamente, em ambas as etapas de amostragem. Dos compostos nitrogenados apenas $\mathrm{O} \mathrm{NO}_{3}$ apresentou teores superiores ao $\mathrm{LD}$, com média de 0,62 mg/L $N$ no mês de julho de 2012 e de 1,42 $\mathrm{mg} / \mathrm{L} \mathrm{N}$ em março de 2014. O comportamento hidroquímico apresentado para as águas do Grupo 2, quando comparado às águas do Grupo 1, sugere uma interferência maior dos aspectos estruturais e hidrodinâmicos nos resultados químicos. No Grupo 2 os poços estão situados nas proximidades do sistema de falhamentos NE-SW e NW-SE, onde o embasamento carbonático Mesozóico encontra-se mais raso e o fluxo subterrâneo modificado em função desses interferentes estruturais. 
Figura 8 - Boxs plots dos parâmetros das águas subterrâneas agrupadas
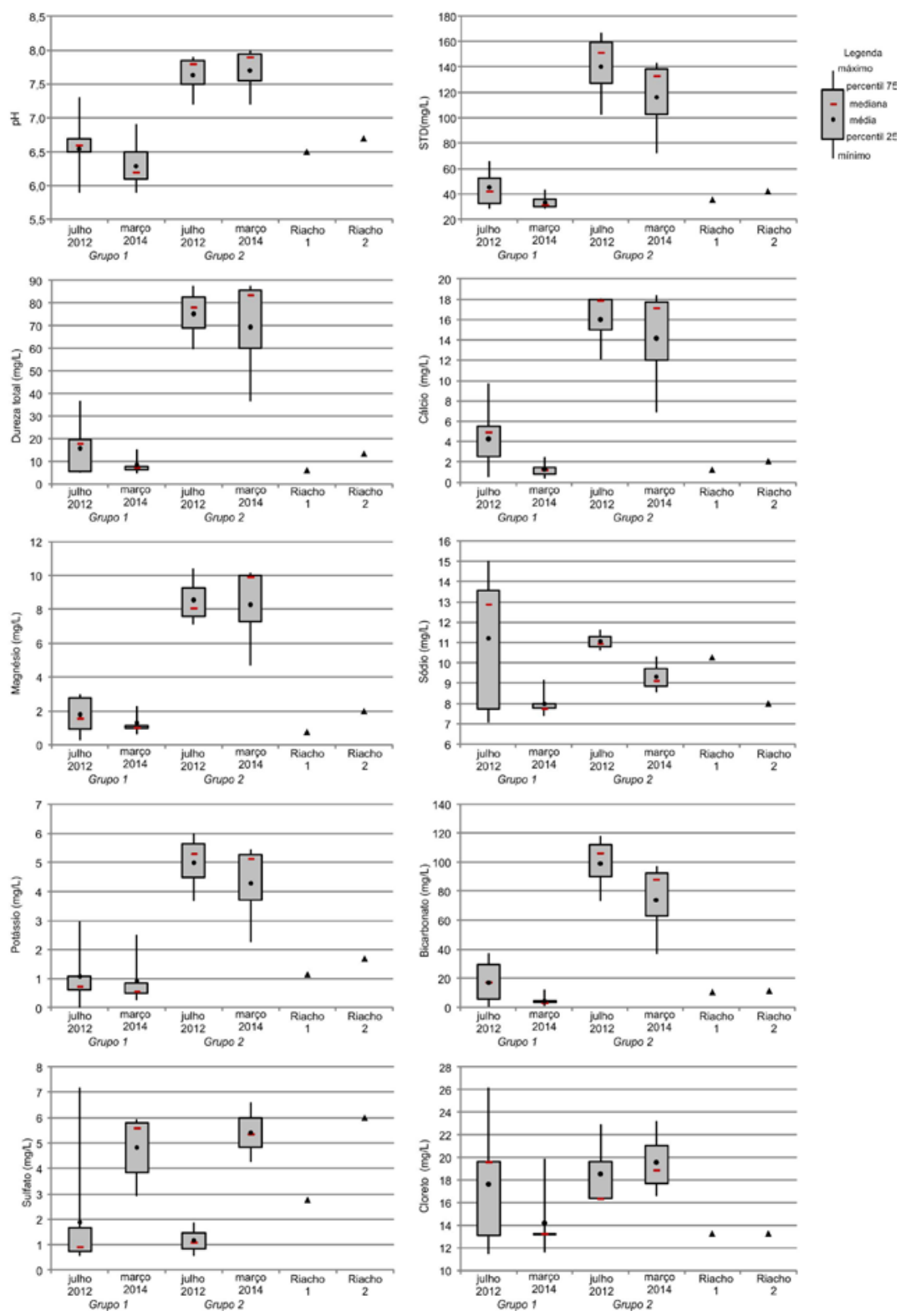

\subsubsection{Evolução hidroquímica}

A Figura 9B apresenta a situação de saturação em calcita e dolomita (Lloyd and Heathcode, 1985) das águas avaliadas. No Grupo 1 as águas são subsaturadas (IS < 1) em calcita e dolomita, devido a percolação em rochas empobrecidas em minerais carbonáticos e/ou devido o tempo de residência curto dessas águas a ponto de não atingir o equilíbrio nesses minerais. Parte das águas do Grupo 2 tendem a situação de equilíbrio (IS = 0), o que ocorre na presença da calcita e dolomita do aquífero sotoposto. Nenhuma amostra se apresentou supersaturada (IS > 1) nesses minerais, situação possível se as águas avaliadas captassem unicamente o aquífero carbonático Mesozóico. Ghesquière et al, 2015; Mondal et. al, 2010). As amostras dispostas no referido diagrama (Figura 9A) mostram que dois mecanismos principais controlam a hidroquímica das águas avaliadas. Nas águas subterrâneas do Grupo 2 predominam os processos de interação água-rocha, onde os teores mais elevados de $\mathrm{Ca}^{2+} \mathrm{e}$ $\mathrm{HCO}_{3}$ - que influenciam nas razões utilizadas nos gráficos provavelmente provem da dissolução das rochas carbonáticas que compõem o pacote Mesozóico, esses íons são também responsáveis pela maiores concentração iônica dessas águas que se reflete na elevação do STD. Nas águas do Grupo 1 a hidroquímica é influenciada pela precipitação pluviométrica, que constitui a fonte de recarga direta do aquífero Barreiras.

\section{CONCLUSÕES}

As investigações apoiadas em métodos geofísicos, hidrogeológicos e hidrogeoquímicos permitiram um melhor entendimento da influência da compartimentação estrutural no funcionamento local do aquífero Barreiras na área da Boa Cica.

Foram identificados dois grupos de águas que sugerem a ocorrência de processos hidrogeoquímicos distintos: 
(i) No Grupo 1, as águas do aquífero Barreiras são cloretadas sódicas, com STD inferior a 65,41 mg/L, apresentam pH levemente ácido e são brandas em relação a dureza total. Essas águas refletem a rápida recarga proveniente da precipitação pluviométrica e a subsaturação em calcita e dolomita ajuíza o arcabouço siliciclástico do aquífero, pobre nesses minerais.

(ii) As águas do Grupo 2 tendem a serem bicarbonatadas mistas, com STD médio de 140,33 no período úmido e $116,26 \mathrm{mg} / \mathrm{L}$ no período seco, são levemente alcalinas e tendem a águas pouco duras. A geoquímica dessas águas reflete um processo mais acentuado de interação água-rocha e a situação tendendo ao equilíbrio em relação a calcita e dolomita indica que esses minerais carbonatados podem exercer influência na composição química dessas águas subterrâneas. 0 componente estrutural, controlado pelo padrão das falhas nas direções
NE-SW e NW-SE exerce influência sobre essas águas, sugerindo a mistura de águas mediante drenança vertical ascendente entre o aquitardo carbonático e o aquífero Barreiras, onde as descontinuidades tectônicas localmente estariam atuando como conduto de ligação entre ambas as unidades, alimentando o aquífero Barreiras com águas de circulação profunda. Essa hidroquímica pode também ser influenciada pelas reações de dissolução envolvendo o maciço carbonático no local em que o fluxo do aquífero Barreiras intercepta a barreira impermeável originada da falha de Boa Cica.

Considerando a situação do bombeamento dos poços em regime contínuo para abastecimento do sistema adutor, recomenda-se o monitoramento da qualidade da água dos poços produtores, haja vista a possibilidade de um crescente aporte de águas do Grupo 2 nas águas do Grupo 1.

Figura 9 - A) Diagrama de Gibbs para avaliar mecanismos que controlam a qualidade da água subterrânea. B) Relação entre os índices de saturação da calcita e da dolomita
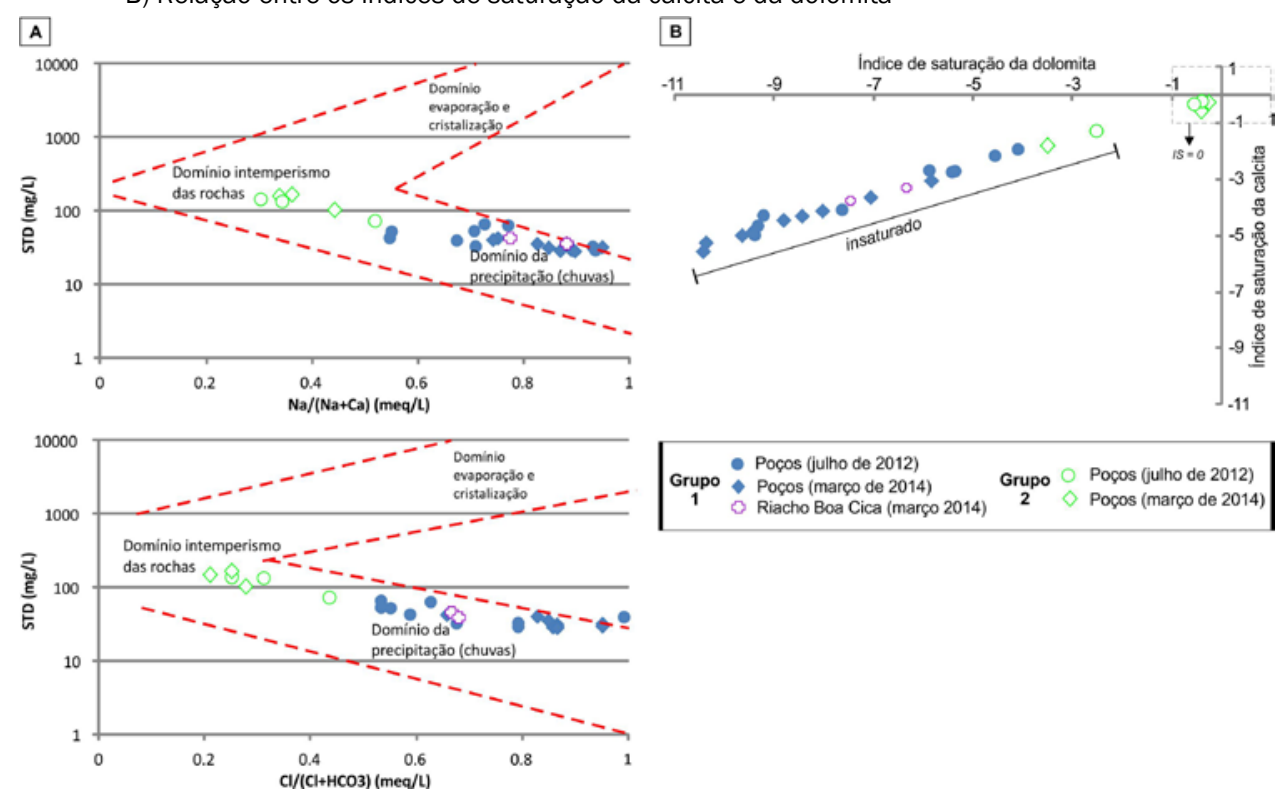

\section{AGRADECIMENTOS}

À Secretaria de Estado do Meio Ambiente e dos Recursos Hídricos do Rio Grande do Norte - SEMARH pela disponibilização dos dados apresentados no artigo, sobretudo ao Programa Semiárido Potiguar que através de financiamento do Banco Mundial executou a obra de ampliação do Sistema Adutor Monsenhor Expedito. Agradecimento especial ao hidrogeólogo Elmo Marinho de Figuerêdo, responsável técnico dos poços, pelas discussões durante a elaboração do artigo.

\section{REFERÊNCIAS}

ANA. Estudos Hidrogeológicos para a orientação do manejo das águas subterrâneas da Região Metropolitana de Natal (RMN). Agência Nacional de Águas: Brasília - DF, 2012.

ANDRADE-FILHO, C. O., ROSSETTI, D. F., BEZERRA, F. H. R., MEDEIROS, W. E., VALERIANO, M. M., CREMON, E. H. \& OLIVEIRA, R. G. Mapping neogene and quaternary sedimentary deposits in northeastern Brazil by integrating

geophysics, remote sensing and geological field data. Journal of South American Earth Sciences, v. 56, 316-327, 2014.

ANGELIM, L. D. A., NESI, J. R., TORRES, H. H. R., MEDEIROS, V. C., SANTOS, C. A., VEIGA JÚNIOR, J. P., \& MENDES, V.A. Geologia e recursos minerais do Estado do Rio Grande do Norte. Escala 1:500.000. Texto explicativo dos mapas geológico e de recursos minerais do Estado do Rio Grande do Norte. Programa de Geologia do Brasil - PGB. Mapeamento geológico. Integrações Geológicas Regionais. CPRM - Serviço Geológico do Brasil, Recife, 2006.

APHA, AWWA \& WEF. Standard methods for the examination of water \& wastewater (21st ed). Washington, DC, USA, 2005.

APPELO, C. A. J., \& POSTMA, D. Geochemistry, groundwater and pollution (2nd ed.). Leiden, The Netherlands, A.A. Balkema, 2005.

BALSAMO, F., STORTI, F., SALVINI, F., SILVA, A. T., \& LIMA, C. C. Structural and petrophysical evolution of extensional fault zones in low-porosity, poorly lithified sandstones of the Barreiras Formation, NE Brazil. Journal of Structural Geology, v. 32, n. 11, p. 1806-1826, 2010.

BARBOSA, J. A., NEUMANN, V. H., LIMA FILHO, M., SOUZA, E. D., \& MORAES, M. D. Estratigrafia da faixa costeira Recife-Natal (bacia da Paraíba e plataforma de Natal), NE Brasil. Estudos geológicos, v. 17, n. 2, p. 3-30, 2007. 
BEZERRA, F. H. R. Neotectonics in northeastern Brazil. Ph.D. Thesis, University of London, London, UK, 1998.

BEZERRA, F. H., \& VITA-FINZI, C. How active is a passive margin? Paleoseismicity in northeastern Brazil. Geology, v. 28, n. 7, p. 591-594, 2000.

BEZERRA, F. H., AMARO, V. E., VITA-FINZI, C., \& SAADI, A. PlioceneQuaternary fault control of sedimentation and coastal plain morphology in NE Brazil. Journal of South American Earth Sciences, v. 14, n. 1, p. 61-75, 2001.

CABRAL, N. M. T., RIGHETTO, A. M., \& QUEIROZ, M. A. Comportamento do nitrato em poços do aqüífero Dunas/Barreiras nas explotações Dunas e Planalto, Natal, RN, Brasil. Eng Sanit Ambient, v. 14, n. 3, p. 299-306, 2009.

CHIHI, H., DE MARSILY, G., BELAYOUNI, H., \& YAHYAOUI, H. Relationship between tectonic structures and hydrogeochemical compartmentalization in aquifers: Example of the "Jeffara de Medenine" system, south-east Tunisia. Journal of Hydrology: Regional Studies, v. 4, p. 410-430, 2015.

CUSTODIO, E. \& LLAMAS, M. R. Hidrología subterranean (2nd ed.). Ômega, Barcelona, 1983.

DINIZ, J. A. O., MONTEIRO, A. B., SILVA, R. C., DE PAULA, T. L. F. Mapa hidrogeológico do Brasil ao milionésimo. Nota técnica. CPRM - Serviço Geológico do Brasil, Recife, 2014.

DOMENICO, P. A. \& SCHWARTZ, F. W. Physical and chemical hydrogeology (2nd ed.). Ed. John Wiley \& Sons. New York, USA, 1998.

DREVER, J. I. The geochemistry of natural waters: surface and groundwater environments (3rd ed.). Prentice Hall, London, 2002.

EMPARN. Monitoramento Pluviométrico. Empresa de pesquisa agropecuária do RN. Disponível em: http://186.250.20.84/monitoramento/monitoramento.php, 2015.

FEITOSA, E. C., FEITOSA, F. C., \& LIRA, H. M. P. Relações estratigráficas e estruturais entre a Bacia Potiguar e a Bacia Costeira PE/PB/RN - Uma hipótese de trabalho. Trabalho apresentado no XII Congresso Brasileiro de Águas Subterrâneas, Florianópolis/SC. Associação Brasileira de Aguas Subterrâneas, 2002.

FEITOSA, F.A.C. Hidrogeologia: conceitos e aplicações. 3. ed. rev. e ampl. Rio de Janeiro: CPRM: LABHID, 2008. 812p.

FONSECA, V. P., SOUZA, M. O. L., SILVA, F. O., BEZZERRA, F. H. R., AMARAL, R. F., SOUZA, Z. S. Carta Geológica. Folha Natal. Escala 1:100.000. Pro grama de Geologia do Brasil - PGB. Mapeamento geológico. CPRM - Serviço Geológico do Brasil, Recife, 2012.

GHESQUIÈRE, O., WALTER, J., CHESNAUX, R., \& ROULEAU, A. Scenarios of groundwater chemical evolution in a region of the Canadian Shield based on multivariate statistical analysis. Journal of Hydrology: Regional Studies, v. 4, p. 246-266, 2015.

GIBBS, R. J. Mechanisms controlling world water chemistry. Science, v. 170 , n. 3962, p. 1088-1090, 1970.

HUSSIN, N. H., YUSOFF, I., TAHIR, W. Z. W. M., MOHAMED, I., IBRAHIM, A. I. N., \& RAMBLI, A. Multivariate statistical analysis for identifying water quality and hydrogeochemical evolution of shallow groundwater in Quaternary deposits in the Lower Kelantan River Basin, Malaysian Peninsula. Environmental Earth Sciences, v. 75, n. 14, p. 1-16, 2016.

IPT. Estudo Hidrogeológico Regional do Estado do Rio Grande do Norte (Report 15795). Instituto de Pesquisas Tecnológicas do Estado de São Paulo: São Paulo - SP, 1982.

KIRSCH, R. Groundwater Geophysics, a tool for hydrogeology (2nd ed.) Springer, Berlin, 2006.

LLOYD, J. W., \& HEATHCOTE, I. Natural Inorganic Hydrochemistry in Relation to Groundwater (1st ed.). Oxford University Press, New York, 1985.

LUCENA, L. R. F. Implicações tectônicas na hidrologia do Aquífero Barreiras e Sistema Lacustre do Bonfim, Nísia Floresta-RN. Dissertação (Mestrado) Natal: Universidade Federal do Rio Grande do Norte (UFRN), 1999.
LUCENA, L. R. F. Implicação da compartimentação estrutural no Aqüífero Barreiras na área da bacia do Rio Pirangi-RN. Tese (Doutoramento). Curitiba: Universidade Federal do Paraná (UFPR), 2005

LUCENA, L. R. F. O condicionamento por falhas geológicas de um aquífero freático. Nivas Edições Acadêmicas, Brasil, 2018. 151p.

LUCENA, L. R. F., \& DE QUEIROZ, M. A. Considerações sobre as influências de uma tectônica cenozóica na pesquisa e prospecção de recursos hídricos-o exemplo do litoral sul de Natal-RN, Brasil. Águas Subterrâneas, v. 15, n. 1, p. 81-88, 1996.

LUCENA, L. R. F., DE OLIVEIRA JR, J. G., DE MEDEIROS, W. E., \& DE QUEIROZ, M. A. The potential of the Barreiras aquifer in the lower course of the Doce River, Rio Grande do Norte State, northeast Brazil - Integration of hydrogeological and geophysical data. Revista Brasileira de Geofísica, v. 31, n. 1, p. 43-57, 2013

MCNEELY, R. N., NEIMANIS, V. P., \& DWYER, L. Water quality sourcebook: a guide to water quality parameters. In Water Quality Sourcebook: A guide to water quality parameters. Environment Canada, 1979.

MEDEIROS, W. E., \& SILVA, J. B. Geophysical inversion using approximate equality constraints. Geophysics, v. 61, n. 6, p. 1678-1688, 1979.

MELO, J. G. Impactos do desenvolvimento urbano nas águas subterrâneas de Natal, RN. Zona sul. Tese (Doutoramento) - São Paulo: Universidade de São Paulo (USP), 1995.

MONDAL, N. C., SINGH, V. P., SINGH, V. S., \& SAXENA, V. K. Determining the interaction between groundwater and saline water through groundwater major ions chemistry. Journal of Hydrology, v. 388, n. 1, p. 100-111, 2010.

NOGUEIRA, F. C. C., BEZERRA, F. H. R., \& CASTRO, D. L. 2006. Deformação rúptil em depósitos da Formação Barreiras na porção leste da Bacia Potiguar. Geologia USP, Série Científica, v. 6, n. 2, 51-59, 2006.

NOGUEIRA, F. C. C., BEZERRA, F. H. R., CASTRO, D. L., \& BRANCO, R. M. G. C. Radar de Penetração no Solo (GPR) aplicado ao estudo de estruturas tectônicas neógenas na Bacia Potiguar-NE do Brasil. Revista de Geologia, v. 19, n. 1, p. 23-33, 2005.

ORELLANA, E. Prospección geoeléctrica en corriente continua. Ed. Paraninfo. Madrid, 1972.

PARKHURST, D. L., \& APPELO, C. A. J. Description of input and examples for PHREEQC version 3 - a computer program for speciation, batch-reaction, one-dimensional transport, and inverse geochemical calculations. US geological survey techniques and methods, book, 6, 497, 2013.

PESSOA NETO, O. D. C., SOARES, U. M., SILVA, J. D., ROESNER, E. H., FLO RENCIO, C. P., \& SOUZA, C. D. Bacia Potiguar. Boletim de Geociências da Petrobras, v. 15, n. 2, p. 357-369, 2007.

Piper, A. M. A graphic procedure in the geochemical interpretation of water analyses. Eos, Transactions American Geophysical Union, v. 25, n. 6, p. 914-928, 1944.

REIS, Á. F., BEZERRA, F. H., FERREIRA, J. M., NASCIMENTO, A. F., \& LIMA, C. C. Stress magnitude and orientation in the Potiguar Basin, Brazil: Implications on faulting style and reactivation. Journal of Geophysical Research: Solid Earth, v. 118, n. 10, p. 5550-5563, 2013.

RODRIGUES, M. D. A. C., SOUZA, I. V. F. D., \& LUCENA, L. R. F. D. Preliminary geometric model of the Barreiras Aquifer derived from hydrogeophys ics data at the River Catu basin, NE Brazil. In 12th International Congress of the Brazilian Geophysical Society \& EXPOGEF, Rio de Janeiro, Brazil, 1518 August 2011 (pp. 731-735). Society of Exploration Geophysicists and Brazilian Geophysical Society, 2011.

ROSSETTI, D. F., BEZERRA, F. H., \& DOMINGUEZ, J. M. Late oligocene: miocene transgressions along the equatorial and eastern margins of Brazil. Earth-Science Reviews, v. 123, p. 87-112, 2013.

SCHOELLER, H. Utilite de la notion des exchanges de bases pour le comparison des eaux souterraines. Société Géologie Comptes Rendus Sommaire et Bulletin, série, 5, 651-657, 1935. 
SEMARH. Estudos hidrogeológicos para a orientação do manejo das águas subterrâneas do litoral norte à região Metropolitana de Natal (Bloco Litoral Norte). Secretaria de Estado do Meio Ambiente e dos Recursos Hídricos do Rio Grande do Norte: Natal - RN, 2012a.

SEMARH. Estudos hidrogeológicos para a orientação do manejo das águas subterrâneas do litoral sul à região Metropolitana de Natal (Bloco Litoral Sul). Secretaria de Estado do Meio Ambiente e dos Recursos Hídricos do Rio Grande do Norte: Natal - RN, 2012b.

SERHID. Caracterização Hidrogeológica dos Aquíferos do Rio Grande do Norte. Plano Estadual dos Recursos Hídricos. Secretaria de Recursos Hídricos do Estado do Rio Grande do Norte: Natal - RN, 1998a.
SERHID. Caracterização Hidroquímica dos aqüíferos do Rio Grande do Norte e estudos de vulnerabilidade. Plano Estadual dos Recursos Hídricos. Secretaria de Recursos Hídricos do Estado do Rio Grande do Norte: Natal $\mathrm{RN}, 1998 \mathrm{~b}$.

STEIN, P., DINIZ FILHO, J. B., DE LUCENA, L. R. F., \& CABRAL, N. M. T. Qualidade das águas do aquífero Barreiras no setor sul de Natal e norte de Parnamirim, Rio Grande do Norte, Brasil. Revista Brasileira de Geociências, 42(suppl. 1), 226-237, 2012.

STIFF JR, H. A. The interpretation of chemical water analysis by means of patterns. Journal of Petroleum Technology, v. 3, n. 10, p. 15-3, 1951. 